\title{
Diving under the influence: issues in researching personality and inert gas narcosis
}

\author{
Charles H. Van Wijk, Jarred H. Martin, Willem A.J. Meintjes
}

Institute for Maritime Medicine, Simon's Town; Faculty of Medicine and Health Sciences, Stellenbosch University, South Africa

\begin{abstract}
Background: This paper considers the relationship between measures of personality and mood states, and susceptibility to inert gas narcosis. It briefly reviews the topics of inert gas narcosis affecting personality, and personality affecting the susceptibility to inert gas narcosis. There appears to be is a theoretical argument for a possible relationship between measures of personality, mood states, and susceptibility to narcosis. Practically, such a relationship may speak to issues in selection, training and preparation, risk assessments, and even accident investigation in the diving and/or hyperbaric environment.

Materials and methods: Twenty one divers completed measures of personality and mood states, and were then compressed to $709 \mathrm{kPa}$ (equivalent to $60 \mathrm{msw}$ ) in a dry compression chamber, where they completed a task measuring speed of information processing, and a scale measuring subjective narcosis.

Results and Conclusions: The main finding was the absence of any significant correlations between measures of personality traits and mood, and susceptibility to inert gas narcosis. Although the study found no evidence of any major relationship, it is presented as a case study to highlight some of the issues and pitfalls involved in such research. The lessons learned - including the careful defining and describing of concepts, and choosing of samples and measurements - are used to discuss some of the methodological and conceptual issues and future directions for researchers to consider.
\end{abstract}

(Int Marit Health 2017; 68, 1: 52-59)

Key words: nitrogen narcosis, personality, mood states, diving, hyperbaric

\section{INTRODUCTION}

Interest in personality correlations to behaviour or performance remains universal, and this extends also to the diving environment. However, in spite of numerous studies of personality and diving generally, there is no clarity on the association between measures of personality and susceptibility to inert gas narcosis (IGN), a condition associated with deep diving. Although there were earlier attempts [1], changes in nomenclature and measuring techniques over time make older studies difficult to interpret, and current studies using updated terminologies and measurements appear sparse.

Reports in both the popular and academic diving literature seem to suggest an association between personality and IGN, including effects of IGN on personality, and effects of personality on performance under conditions of IGN. This article will briefly discuss these two issues, where after it will report on a pilot study exploring associations between personality and susceptibility to IGN. The lessons learned from it will be used to discuss some of the methodological issues and future directions for researchers to consider.

\section{PERSONALITY CHANGES DURING INERT GAS NARCOSIS}

The hypothesised effect of nitrogen narcosis on personality has been referred to in older diving texts [2] and suggested in older studies [1]. The paucity of research using modern nomenclature and conceptualisation resulted in the current situation where more speculative literature, particularly on the internet, has become the reference point for the hypothesis that IGN is causally associated with temporary changes in 'personality'. Although there is no uniformly accepted definition of personality, contemporary definitions do coalesce in their reference to personality 
being constituted through the formation of enduring and dispositional patterns of thinking, feeling, and behaving which can be evidenced across a variety of situations $[3,4]$. Per definition, personality does not change easily.

Careful reading of reported changes during deep dives reveals that it often refers to experiences like irritability, aggressiveness, euphoria, and disinhibition, which could be interpreted as mood states or symptoms. Transient mood state changes during hyperbaric compression have been well documented within diving medical literature $[5,6]$.

Updated nomenclature in scientific psychology may lead to different interpretations of the terminology used in earlier discussions of personality and narcosis, where mood and personality might have been used interchangeably, and also due to the lack of uniform definitions of personality.

If personality refers to relatively stable traits (and we contend that it does), then it is unlikely that IGN, as a temporary narcotic influence, would be causally associated with short-term changes in personality. Changed personal expressions during deep dives more likely reflect changes in mood states rather than changes in personality.

\section{PERSONALITY AS PREDICTOR OF THE EXPRESSION OF, OR SUSCEPTIBILITY TO, IGN}

It is widely accepted that personality influences behaviours, attitudes, and subjective experiences [7]. It is thus possible to hypothesise that personality could also influence the susceptibility to IGN. One ready example is the association between personality and alcohol intoxicated behaviours [8]. However, apart from the evolving terminologies discussed above, there appears to be little direct evidence to claim that personality or mood states have a definitive effect on susceptibility to (e.g. expression or experience of) IGN.

The notable exception is anxiety, which appears to exacerbate the effects of narcosis, and especially the impairment of psychomotor functioning [9-12]. Two recent studies $[11,13]$ have suggested that anxiety aggravates narcosis in a synergistic way to magnify functional impairment.

Other factors reported to affect susceptibility to IGN in diving and hyperbaric environments include apprehension, task loading, cold, fatigue, exercise, sedatives, alcohol, and increased levels of $\mathrm{CO}_{2}$, which all increase the level of narcosis at a given depth $[5,6,14]$. Conversely, frequent or prolonged exposure, high intelligence, and diving experience have been suggested to reduce the effect of narcosis [15], although the empirical support for this remains non-definitive.

In conclusion, the role of personality or mood as predictors of the susceptibility to IGN has not yet been clarified. Apart from the academic interest in any relationship between personality and IGN, it may also have important practical applications. Such a relationship may speak to issues in selection, training and preparation, risk assessments, and even accident investigation in the diving and/ /or hyperbaric environment, and therefore remains a worthwhile topic of investigation.

\section{PILOT STUDY}

Given the paucity of current research on personality and susceptibility to IGN, we conducted a pilot study to test its associations using a convenience sample of naval divers. The pilot study aimed to explore associations between both dispositional personality and transient mood states, and the effect of IGN. IGN was measured by both neuropsychological performance and subjective ratings. The purpose was to describe any associations between personality inventory and transient mood states scores on the one hand, and objective and subjective measures of the effect of IGN. Apart from reporting the outcome here, we also use it as a case study to discuss some of the issues and pitfalls involved in this type of research.

\section{MATERIALS AND METHODS DEFINING TERMINOLOGY}

Personality was operationalised using trait theory. Dispositional traits have two classic properties, namely that they are substantially stable over time, and that they are broadly consistent across different situations and contexts. Personality traits thus refer to enduring characteristics that are visible throughout the range of life's experiences. While this reflects an all-encompassing definition, two specific models of trait personality were tested, and further defined here.

Firstly, character traits can be organised into dimensions or factors of personality. The five-factor model proposes five overarching domains that have been found to contain and subsume most known personality traits, and are assumed to represent the basic structure behind all personality traits $[16,17]$. The five dimensions are 'extraversion', 'agreeableness', 'conscientiousness', 'neuroticism', and 'openness to experience'.

Secondly, personality traits can be organised using an emotional disposition framework, where people's emotional disposition predicts the tendency towards the type of experience they have, and includes 'anxiety', 'curiosity', 'anger', and 'depression' [18].

Mood states were defined as "a set of feelings, ephemeral in nature, varying in intensity and duration and usually involving more than one emotion" [19]. Mood states are usually understood to be transient and situational (as opposed to permanent and dispositional traits). In this definition, predive mood states may affect performance under conditions of IGN through the mechanism of increased arousal (e.g. in elevated 'tension', 'anger', or 'vigour') or decreased arousal 
(e.g. 'depression'), or through distraction (e.g. the presence of strong mood-content), or through a mood state of fatigue and exhaustion.

Susceptibility to narcosis was described in terms of both objective (i.e. neuropsychological) performance decrements, and subjective ratings of symptoms while under condition of narcosis.

\section{STUDY DESIGN}

The pilot study used a convenience sample of navy divers conducting scheduled work-up dives. For the divers, the study protocol was additional to the scheduled task of exposure to deep diving conditions. As the study used participants who were available, no a priori power analyses were done to determine optimal sample size.

The divers completed the Big Five Inventory-44 (BFI), State-Trait Personality Inventory, trait subscales (STPI), and Brunel Mood Scale (BRUMS) in a class-room setting prior to their chamber session. They also completed the Digit Symbol Modalities Test (DSMT) in a hyperbaric chamber at normobaric pressure (101 kPa).

Within $4 \mathrm{~h}$ they also completed a chamber session to $709 \mathrm{kPa}$, and completed the DSMT (alternative version) at depth, as well as the Subjective Narcosis Assessment Scale (SNAS) before decompression. The order of administration (surface and depth) was counterbalanced across participants.

Score differences between the 709 and $101 \mathrm{kPa}$ sessions were calculated to obtain an Index of Susceptibility to Narcosis (ISN), and this was correlated with personality measures (i.e. BFI and STPI), mood states (i.e. BRUMS), and measures of subjective experience of IGN (i.e. SNAS).

Ethical clearance was obtained from the Stellenbosch University Health Research Ethics Committee.

\section{PARTICIPANTS}

The participants were active duty divers, who recently completed their navy diving course, and were participating in the chamber session as part of their clearance diving work-up schedule. They were all healthy and in possession of a medical certificate for hyperbaric exposure. The group consisted of 2 women and 19 men, with a mean age of $22.5 \pm 0.9$ years, and 12 years of formal education.

\section{MEASURES}

Personality traits according to the five-factor model were measured using the self-report BFI. It consists of 44 items with short phrases and relatively accessible vocabulary [20, 21].

Personality traits according to the emotional disposition model were measured using the self-report STPI. The four trait subscales were used in this study, consisting of
40 items measuring dispositional anxiety, curiosity, anger, and depression in adults [22].

Transient mood states were measured using the BRUMS. The 24-item self-report inventory measures six identifiable affective states, namely the transient mood states of tension, depression, anger, vigour, fatigue and confusion $[23,24]$. The BRUMS can be used with different instruction sets, and the "How you feel right now" instruction set was utilised in this study.

Susceptibility to narcosis was measured objectively through neuropsychological performance decrements, using the DSMT. The DSMT comes from the Wechsler Adult Intelligence Scale-III and measures speed of information processing $[25,26]$. It was used in its standard instruction format for coding. Practice effects can be controlled when alternative forms are used [27]. Two parallel forms were available, and were used alternatively. The difference between the normobaric and hyperbaric administrations of the DSMT was used as the ISN.

Susceptibility to narcosis was measured subjectively using the SNAS. This self-report rating scale consists of 10 items of subjective symptoms of narcosis, collated into four factors, namely euphoria, anxiety, cognitive suppression, and feeling faint [28].

\section{HYPERBARIC CONDITIONS}

The divers conducted a dry chamber session, on air, to a pressure of $709 \mathrm{kPa}$ (equivalent to $60 \mathrm{msw}$ ). They compressed to this depth at a rate of $1 \mathrm{~m}$ every $3 \mathrm{~s}$ (total compression time $180 \mathrm{~s}$ ). Temperature at depth was maintained between $26^{\circ} \mathrm{C}$ and $29^{\circ} \mathrm{C}$.

The depth was determined by the scheduled work-up dives, and is deeper than what would typically be found during open-water diving on air. Because of the increased pressure, a greater effect of narcosis was expected, although the chamber sessions were without the attentional demands of open water environments.

\section{STATISTICAL ANALYSIS}

The data was analysed using statistical software ("SPSS 23"). Firstly, the sample was described in terms of the measuring instrument profiles (BFI, STPI, BRUMS, and DSMT). Secondly, the IGN effect was described in terms of performance decrements and subjective experiences (SNAS). Thirdly, all psychometric measures of personality traits and mood were correlated to the ISN, to determine associations between the constructs.

All the psychometric score profiles were normally distributed, which allowed the use of parametric statistics, namely t-test for paired samples to compare DSMT performance across conditions, and Pearson's $r$ for correlational analysis. A p-value of $<0.05$ was considered significant. 


\section{RESULTS}

\section{PSYCHOMETRIC PROFILES OF SAMPLE}

The BFI means and standard deviations are presented in Table 1. The recently qualified navy divers displayed elevated scores for the agreeableness and conscientiousness factors, higher than general population and recreational scuba diver samples. On the neuroticism factor they scored lower than general population and recreational scuba diver samples [29, 30].

The STPI means and standard deviations are presented in Table 1. Trait anxiety, anger, and depression were markedly lower than the original norms [22]. BRUMS scores (Fig. 1) showed the expected iceberg profile [31], with a slight elevation in fatigue. The means and standard deviations are presented in Table 1.

Table 1. Psychometric profile of recently qualified navy divers

\begin{tabular}{|c|c|c|c|}
\hline & Mean & SD & Range \\
\hline \multicolumn{4}{|l|}{ Big Five Inventory-44 } \\
\hline Extraversion & 3.70 & 0.48 & $2.88-4.63$ \\
\hline Agreeableness & 4.07 & 0.59 & $2.56-5.00$ \\
\hline Conscientiousness & 4.11 & 0.54 & $3.11-5.00$ \\
\hline Neuroticism & 2.19 & 0.51 & $1.25-3.00$ \\
\hline Openness & 3.75 & 0.46 & $2.50-4.40$ \\
\hline \multicolumn{4}{|l|}{ State-Trait Personality Inventory } \\
\hline Anxiety & 15.5 & 2.7 & $12-23$ \\
\hline Curiosity & 30.2 & 3.8 & $21-37$ \\
\hline Anger & 19.0 & 4.1 & $13-27$ \\
\hline Depression & 14.3 & 2.6 & $10-21$ \\
\hline \multicolumn{4}{|l|}{ Brunel Mood Scale } \\
\hline Tension & 2.2 & 2.2 & $0-9$ \\
\hline Depression & 0.7 & 1.2 & $0-4$ \\
\hline Anger & 2.7 & 2.9 & $0-10$ \\
\hline Vigour & 12.3 & 2.5 & $7-16$ \\
\hline Fatigue & 5.1 & 3.4 & $2-13$ \\
\hline Confusion & 1.9 & 2.5 & $0-9$ \\
\hline \multicolumn{4}{|c|}{ Subjective Narcosis Assessment Scale } \\
\hline Total score & 17.9 & 12.3 & $0-41$ \\
\hline Factor 1: Euphoria & 10.2 & 6.3 & $0-20$ \\
\hline Factor 2: Anxiety & 1.2 & 1.8 & $0-6$ \\
\hline Factor 3: Cognitive suppression & 3.0 & 3.8 & $0-11$ \\
\hline Factor 4: Feeling faint & 3.6 & 3.8 & $0-12$ \\
\hline \multicolumn{4}{|l|}{ Digit Symbol Modalities Test } \\
\hline Score at $101 \mathrm{kPa}$ & 62.1 & 11.5 & $47-92$ \\
\hline Score at $709 \mathrm{kPa}$ & 45.5 & 16.1 & $22-93$ \\
\hline
\end{tabular}

SD - standard deviation

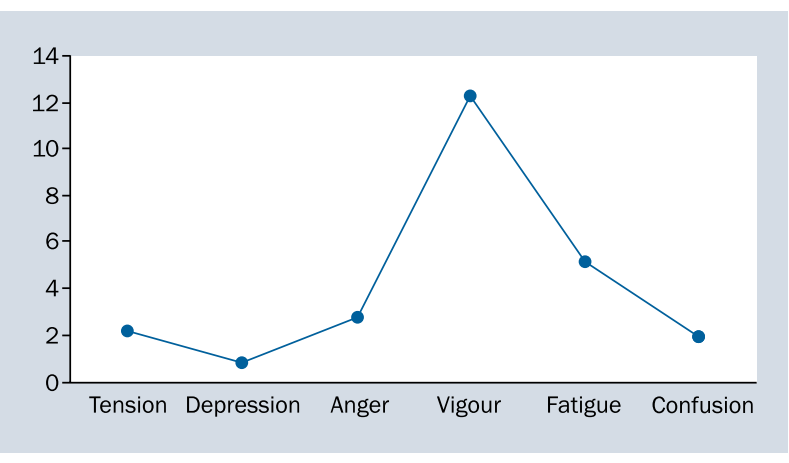

Figure 1. Brunel Mood Scale (BRUMS) profile of recently qualified navy divers

The baseline DSMT (at $101 \mathrm{kPa}$ ) means and standard deviations are presented in Table 1 . There was a large variation in performance across the sample.

\section{EFFECT OF IGN}

The DSMT at $709 \mathrm{kPa}$ means and standard deviations are presented in Table 1. There was an increased variation in performance across the sample. The difference between the normobaric and hyperbaric administrations of the DSMT was used as the ISN, and represented a $26.7 \%$ decrement in performance at $709 \mathrm{kPa}$ in a dry hyperbaric chamber on this speed of information processing task. The mean score difference was highly significant $(t=8.865$, $p<0.0001$ ).

On a more practical level, as mentioned, 60 msw lies on the outer extreme for air diving, and it is unlikely that divers will regularly descend to such depths on air to work. This study was conducted in a dry chamber with the competing attentional demands from an open-water environment absent, and it could be hypothesised that slightly shallower depths in open water may have similar effects.

On the SNAS only factor 1 was subscribed to, with some participants reporting feelings of euphoria. Other experiences were infrequently reported (Table 1), with factor 2 , anxiety, the least endorsed.

\section{CORRELATIONAL STATISTICS}

In terms of subjective narcosis, there were no significant correlations between the ISN and any of the four SNAS factors. With regards to personality traits, no significant correlations where found between the big five factors or the four STPI traits and susceptibility to IGN (Table 2) either. Similarly, no significant correlations where found between the six BRUMS mood states, and susceptibility to IGN (Table 2). All correlations reported in Table 2 had low power of analysis, generally below $40 \%$, which was largely attributable to the small sample size. 
Table 2. Correlations between inert gas narcosis and personality trait and mood scores

\begin{tabular}{|c|c|c|c|c|c|}
\hline & $\mathbf{r}$ & $\mathbf{p}$ & & $\mathbf{r}$ & $\mathbf{p}$ \\
\hline BFI & & & BRUMS & & \\
\hline Extraversion & -0.23 & 0.32 & Tension & -0.32 & 0.18 \\
\hline Agreeableness & 0.13 & 0.59 & Depression & 0.11 & 0.67 \\
\hline Conscientiousness & 0.09 & 0.69 & Anger & 0.03 & 0.91 \\
\hline Neuroticism & -0.05 & 0.85 & Vigour & -0.36 & 0.14 \\
\hline \multirow[t]{2}{*}{ Openness to experience } & -0.04 & 0.87 & Fatigue & 0.32 & 0.18 \\
\hline & & & Confusion & -0.28 & 0.25 \\
\hline STPI & & & SNAS & & \\
\hline Anxiety & 0.09 & 0.72 & Euphoria & 0.06 & 0.79 \\
\hline Curiosity & -0.39 & 0.10 & Anxiety & 00.7 & 0.46 \\
\hline Anger & -0.04 & 0.88 & Cognitive suppression & 0.26 & 0.26 \\
\hline Depression & 0.20 & 0.40 & Feeling faint & 0.13 & 0.58 \\
\hline
\end{tabular}

BFI - Big Five Inventory-44; BRUMS - Brunel Mood Scale: SNAS - Subjective Narcosis Assessment Scale; STPI - State-Trait Personality Inventory, trait subscales

Further, no significant correlations were found between any of the personality markers and the four SNAS factors, and no significant correlations where found between the mood states scores and SNAS factors.

\section{DISCUSSION}

The homogeneity of the personality profiles of this sample was noteworthy. Navy divers tend to conform to very specific personality profiles $[32,33]$, which in this case may actually be a limitation, as it restricts the range and variability of responses. The very limited age and education range may further have contributed to the narrow profile.

In contrast, the large variation in performance scores (on a test of ability) provided greater variation for subsequent statistical analyses. The large decrement in speed of information processing of about $27 \%$ suggests significant risk to performance at that depth. However, the fact that $60 \mathrm{msw}$ lies at the extreme end of air diving, and the relative inexperience of the divers, may have contributed to impairment additional to the hyperbaric nitrogen narcosis.

There were limited reports of subjective narcosis, mainly restricted to feelings of euphoria, which provided limited variance for statistical analysis. Interestingly, there were no significant correlations between the objective and subjective measures of IGN. Previous reports of significant correlations between SNAS factors 1 and 2 and cognitive performance [28] was not replicated here, possibly due to the limited variance in SNAS responses.

The main finding was the absence of any significant correlations between measures of personality traits and mood, and susceptibility to IGN. It needs to be cautioned that the correlations generally had low power.
The study suffered from a number of limitations, which limit the confidence in the result. The lessons learnt from this will be incorporated into the next section, which deals with methodological issues and future directions.

\section{METHODOLOGICAL ISSUES \\ AND FUTURE DIRECTIONS}

The pilot study did not find any significant relationships between the measures of personality traits, mood states, and susceptibility to IGN. However, the pilot study was a convenience study, with all the constraints associated with such an endeavour, which contributed to low power analyses. Further, the protocol had some methodological limitations, including a small and psychometrically homogenous sample, and a single measure of performance decrement. Yet, there are potentially significant and important real-world applications if the relationship between these variables could be further clarified. Thus we believe it is still a topic worthy of further exploration, and presenting some considerations for future research.

\section{CONTEXT AND ASSOCIATED CONSIDERATIONS}

Future studies need to consider both laboratory (compression chamber) and open water environments, given that open water is typically a psychologically and physically demanding environment. Within the constraints of meaningful experimental control, conditions need to be as realistic as possible, in order to generalise results to the actual practice of diving In this regard, depths appropriate to actual diving practices are recommended, while considering that the additional workload of actual dives may contribute to measureable performance decrement.

Other factors, like pre-dive anxiety and other transient mood states, need to be measured to control for their ef- 
fects during the dive, especially (but not only) in open water conditions.

Closely related to the choice of context is the requirement to carefully define what experimental mechanism or variable is measured in that condition. This pilot study measured the combined effects of factors present under conditions of increased air pressure in a dry compression chamber. This would include the effects of nitrogen narcosis as the likely dominant mechanism, but may also have included the effects of apprehension, or even raised oxygen partial pressures (considering the depth), and so forth. Researchers need to carefully describe which construct involved in the experimental condition they are using, for example measuring the effects of 'pure' IGN (usually meaning nitrogen narcosis) versus a combined effect (which may include effects of raised oxygen or carbon dioxide partial pressures, among other variables) versus open water IGN (with the confounds of competing attentional demands, potential apprehension, physical exertion effects, and so forth).

The choice of context would also influence sample recruitment. Researchers need to remain mindful that pre-selected groups may have highly homogenous psychological profiles which provide restricted variability for correlational analysis. While this is typical of naval divers, and maybe unavoidable in other groups too, larger sample sizes and extended age, gender, and educational ranges may allow for a greater scale of responses. A priori power analyses may be required to determine optimal sample sizes. As the role of sex differences in susceptibility to IGN has not been conclusively determined, future studies may also consider using biometric measures to elucidate other biological contributions.

\section{CONCEPTUALISING SUSCEPTIBILITY TO IGN}

Researchers will need to define and operationalise their understanding of susceptibility to IGN carefully, as it has both theoretical and practical measurement implications. A major limitation of this pilot study was its limited operationalisation of susceptibility to IGN, further hobbled in that it was assumed that performance decrement is an expression of narcosis.

Susceptibility to IGN may need to be operationalised in three ways (or better yet, a combination of them). Firstly, through self-report, namely the subjective experience of divers. However, by the very nature of narcosis research, self-report has limitations. For example, there is a wide range of individual variation in perceiving the onset of narcosis [34]. This pilot study also recorded significant impairment of performance, while participants did not report corresponding subjective experiences of narcosis. The 10-item SNAS may further restrict the possible range of adjectives to describe subjective experience, and longer lists of descriptive words may enhance the self-report component of susceptibility to IGN, as was done previously [35, 36].

Secondly, through objective performance measures. This pilot study used speed of information processing as measure of cognitive performance. Other studies exploring the effects of IGN used different markers tapping into different cognitive functions, which at times may limit comparisons across studies. Neuropsychological performance encompasses a range of domains, and research into susceptibility to IGN may need to employ measures (tests or tasks) over multiple domains to meaningfully investigate performance effects.

Thirdly, through external observations of behavioural performance. The use of checklists of behaviours or symptoms that can be verified by multiple observers may contribute to a more objective and nuanced understanding of the effects of IGN on performance, which can in turn be correlated with pre-dive measures of personality and mood states. Such checklists, consisting of defined behaviour or described symptoms, will need to allow recording for both frequency of behaviours, and the severity of such behaviours.

In this regard it may be useful to work towards developing a 'tool' to measure behaviour. This could consist of a wide range of observable behaviours - each well described/defined - that can be graded on a scale (again with well-defined anchor points). If such a tool can be tested prospectively, and validated appropriately, it could be of great value in a variety of circumstances. It could be used in chambers to both study the effects and correlations of IGN, as well as to train individuals to understand their own susceptibility to IGN - for example through watching a video recording of their own chamber exposures and interpreting their behaviour through such a tool. Further, such a tool could contribute to safety in the commercial diving environment, where video surveillance of deep dives through a Remotely Operated Vehicle or even on divers' helmets are often employed, and voice communication also recorded. Supervisors may be able to more accurately assess susceptibility and risk to performance of dives under conditions of increased IGN.

\section{DEFINITION OF OTHER VARIABLES}

Some of the earlier studies have limited value today due to inadequate definition of mood and personality. Over time, different theoretical models have been developed, which allows for different ways of measuring personality. While this is an advancement, it also carries the risk that an inadequate definition of personality, and the accompanying theoretical basis of its measuring instruments, may limit the usefulness of study results.

To avoid such a situation, this pilot study specifically used two theoretical models and defined each separately. 
It also chose measuring instruments recognised within each theoretical framework. However, the convenience sample of navy divers necessitated the use of brief instruments. The 44-item BFI responses were anchored at 1 and 5 , the 40-item STPI responses at 1 and 4, and the 24-item BRUMS at 0 and 4 . Future research might benefit from employing more detailed inventories, referring to scales with both more items, as well as a larger range of responses, which may allow for greater variability to analyse. The NEO-PI-R [37] is one example of such a personality scale that is well validated and widely accepted. In the same vein, longer mood state scales like the POMS [38] or PANAS-X [39] might also enable a more nuanced measurement.

In spite of the above, it is recognised that divers may not always be keen test-takers, and brief scales may still be more accurate than extended psychological instruments.

\section{STATISTICAL ANALYSES}

Descriptive and correlational statistics is a logical first step, as was used in this pilot study. Where significant findings may occur in future studies, multiple regression analyses could assist in determining the relative effect of the applicable personality and mood variables on susceptibility to IGN. Analyses could further be extended to move beyond descriptive and correlational statistics, to include predictive modelling in cases where significant findings occur.

\section{CONCLUSIONS}

While there is a theoretical argument to be made for a possible relationship between measures of personality, mood states, and susceptibility to narcosis among divers, there is little direct evidence of such a relationship. This pilot study found no significant correlation, although this could also partly be attributed to the methodology employed in the study. However, considering the potential benefits of elucidating the nature of this relationship for diving safety, it remains a topic worthy of further investigation. Using the pilot project as a case study, the lessons learnt from it - for example careful defining and describing of concepts, and the choices of samples and measurements - are presented as issues for future researchers to consider.

\section{REFERENCES}

1. Biersner RJ, Edwards D, Bailey LW. Effects of N2O on responses of divers to personality tests. Percept Mot Skills. 1974; 38(3): 1091-1097, doi: 10.2466/pms.1974.38.3c.1091, indexed in Pubmed: 4607799.

2. Lippmann J. The Essentials of Deeper Sport Diving: An Overview of the Theory and Requirements of Deeper Diving. Locust Valley, NY: Aqua Quest Publications; 1992.

3. APA. Personality [internet]. 2015. Available from. http://www.apa. org/topics/personality/ (cited 01 June 2016).

4. Kazdin AE. editor. Encyclopaedia of Psychology. Washington: American Psychological Association; 2000.
5. Bennett PB. Inert Gas Narcosis. In: Bennett P, Elliott D, editors. The Physiology and Medicine of Diving. London: WB Saunders Company Ltd. ; 1993 p. : 170-193.

6. Lowry C. Inert gas narcosis. In: Edmonds C, Pennefather J, Walker R, editor4s. Diving and Subaquatic Medicine. London: Edward Arnold Publishers Ltd. ; 2002 p : 183-193.

7. De Br, Taylor N. Personality assessment. In: Foxcroft C, Roodt G, editors. Introduction to psychological assessment in the South African context, 4th ed. Cae Town: Oxford University Press; 2013. p. : 185-199.

8. Westmaas J, Moeller S, Woicik PB. Validation of a measure of college students' intoxicated behaviors: associations with alcohol outcome expectancies, drinking motives, and personality. J Am Coll Health. 2007; 55(4): 227-237, doi: 10.3200/JACH.55.4.227-237, indexed in Pubmed: 17319329.

9. Baddeley A, Idzikowski C. Anxiety, manual dexterity and diver performance. Ergonomics. 1985; 28(10): 1475-1482, doi: 10.1080/00140138508963272, indexed in Pubmed: 4076169.

10. Davis FM, Osborne JP, Baddeley AD, et al. Diver performance: nitrogen narcosis and anxiety. Aerosp Med. 1972; 43(10): 1079-1082, indexed in Pubmed: 5076607.

11. Kneller W, Higham P, Hobbs M. Measuring Manual Dexterity and Anxiety in Divers Using a Novel Task at 35-41 m. Aviation, Space, Environl Med. 2012; 83(1): 54-57, doi: 10.3357/asem.3123.2012.

12. Mears JD, Cleary PJ. Anxiety as a factor in underwater performance. Ergonomics. 1980; 23(6): 549-557, doi: 10.1080/ /00140138008924769, indexed in Pubmed: 7202399.

13. Hobbs M, Kneller W. Anxiety and psychomotor performance in divers on the surface and underwater at $40 \mathrm{~m}$. Aviat Space Environ Med. 2011; 82(1): 20-25, indexed in Pubmed: 21235101.

14. Fowler B, Ackles KN, Porlier G. Effects of inert gas narcosis on behavior-a critical review. Undersea Biomed Res. 1985; 12(4): 369-402, indexed in Pubmed: 4082343.

15. Sawatzky D. Is diving addictive? Diver Magazine. [internet]. 2012. Available from. http://divermag.com/is-diving-addictive/ (cited 01 June 2016).

16. Digman JM. Personality Structure: Emergence of the Five-Factor Model. Annual Review of Psychology. 1990; 41(1): 417-440, doi: 10.1146/annurev.ps.41.020190.002221.

17. Goldberg $\mathrm{L}$. The structure of phenotypic personality traits. Am Psychologist. 1993; 48(1): 26-34, doi: 10.1037/0003-066x.48.1.26.

18. Spielberger C, Reheiser E. Assessment of Emotions: Anxiety, Anger, Depression, and Curiosity. Applied Psychology: Health and Well-Being. 2009; 1(3): 271-302, doi: 10.1111/j.1758-0854.2009.01017.x.

19. Lane A, Terry P. The Nature of Mood: Development of a Conceptual Model with a Focus on Depression. J Applied Sport Psychol. 2000; 12(1): 16-33, doi: 10.1080/10413200008404211.

20. John OP, Donahue EM, Kentle RL. The Big Five Inventory-Versions 4a and 54. Berkeley, CA: University of California, Berkeley, Institute of Personality and Social Research; 1991.

21. John OP, Naumann LP, Soto CJ. Paradigm shift to the integrative Big Five trait taxonomy: History, measurement, and conceptual issues. In: John OP, Robins RW, Pervin LA, editors. Handbook of personality: Theory and research. New York, NY: Guilford Press;. 2008: p. 114-158.

22. Spielberger CD. Preliminary manual for the State-Trait Personality Inventory. Tampa, FL: University of South Florida.; 1996.

23. Terry PC, Lane AM, Fogarty GJ. Construct validity of the Profile of Mood States - Adolescents for use with adults. Psychology of Sport and Exercise. 2003; 4(2): 125-139, doi: 10.1016/s14690292(01)00035-8. 
24. Terry PC, Lane AM, Lane HJ, et al. Development and validation of a mood measure for adolescents. J Sports Sci. 1999; 17(11): 861-872, doi: 10.1080/026404199365425, indexed in Pubmed: 10585166.

25. Wechsler D. Wechsler Adult Intelligence Scale, 3rd ed. San Antonio, TX: Harcourt Assessment. ; 1997.

26. Mitrushina MN, Boone KB, Razan J. D’Elia LF. Handbook of normative data for neuropsychological assessment, 2nd ed. New York, NY: Oxford University Press; 2005.

27. Pereira DR, Costa P, Cerqueira JJ. Repeated Assessment and Practice Effects of the Written Symbol Digit Modalities Test Using a Short Inter-Test Interval. Arch Clin Neuropsychol. 2015; 30(5): 424-434, doi: 10.1093/arclin/acv028, indexed in Pubmed: 25994156.

28. van Wijk $\mathrm{CH}$, Meintjes WAJ. Subjective Narcosis Assessment Scale: measuring the subjective experience of nitrogen narcosis. Undersea Hyperb Med. 2014; 41(6): 557-563, indexed in Pubmed: 25562946.

29. Musa G, Seng W, Thirumoorthi T, et al. The Influence of Scuba Divers' Personality, Experience, and Demographic Profile on their Underwater Behavior. Tourism Marine Envir. 2011; 7(1): 1-14, do i: $10.3727 / 154427310 \times 12826772784757$.

30. Srivastava S, John 0, Gosling S, et al. Development of personality in early and middle adulthood: Set like plaster or persistent change? J Personality Social Psychology. 2003; 84(5): 1041-1053, doi: 10.1037/0022-3514.84.5.1041.

31. Devonport TJ, Lane AM, Hanin YL. Emotional States of athletes prior to performance-induced injury. J Sports Sci Med. 2005; 4(4): 382-394, indexed in Pubmed: 24501552.
32. Beckman TJ, Lall R, Johnson WB. Salient personality characteristics among Navy divers. Mil Med. 1996; 161(12): 717-719, indexed in Pubmed: 8990825.

33. Van Wijk C, Waters AH. Personality characteristics of South African navy divers. Undersea Hyperb Med. 2001; 28(1): 25-30, indexed in Pubmed: 11732881.

34. Harding S, Bryson P, Perfect T. Investigating the relationship between simulated depth, cognitive functions and metacognitive awareness. Research Report 256. Plymouth: Diving Diseases Research Centre; 2004.

35. Fowler B, Ackles KN. Narcotic effects in man of breathing 80-20 argon-oxygen and air under hyperbaric conditions. Aerosp Med. 1972; 43(11): 1219-1224, indexed in Pubmed: 4635706.

36. Hamilton K, Laliberté MF, Heslegrave R. Subjective and behavioral effects associated with repeated exposure to narcosis. Aviat Space Environ Med. 1992; 63(10): 865-869, indexed in Pubmed: 1417647.

37. Costa PT, McCrae RR. Revised NEO personality inventory (NEO PI-R) and NEO five-factor inventory (NEO FFI): Professional manual. Odessa, FL: Psychological Assessment Resources; 1992.

38. McNair DM, Lorr M, Droppleman LF. Revised manual for the Profile of Mood States. San Diego, CA: Educational and Industrial Testing Services; 1992.

39. Watson D, Clark LA. The PANAS-X: Manual for the Positive and Negative Affect Schedule - Expanded Form. University of lowa's Institutional Repository; 1994. . http://ir.uiowa.edu/cgi/viewcontent. cgi?article=1011\&context=psychology_pubs (Retrieved on 01 June 2016). 